\title{
Banco do Sul: a Proposta, o Contexto, as INTERrogações e os Desafios ${ }^{(*)}$
}

\author{
Carlos Eduardo Carvalho \\ Allan Batista Gabriel \\ Carolina Silva Pedroso \\ Gabriel Yuji Kobayashi Kaneko ${ }^{(*)}$
}

\begin{abstract}
Resumo: O artigo analisa o processo de criação do Banco do Sul, desde a proposta inicial, lançada por Venezuela e Argentina, em 2007, até a definição do capital e dos estatutos, em meados de 2009, com mais cinco países - Bolívia, Brasil, Equador, Paraguai e Uruguai. O projeto suscita muitas indagações. A diversidade de objetivos apresentados pelos presidentes foi superada com a definição do perfil de Banco de Desenvolvimento, defendido pelo Brasil, mas continuam sendo mencionados objetivos mais amplos. O enraizamento institucional da proposta é reduzido e os dois sócios principais, Brasil e Venezuela, dão sinais contraditórios sobre seu comprometimento com a proposta. Não se sabe como o Banco ganhará força com capital reduzido e mecanismo decisório difícil, dadas as diferenças políticas entre os governos. Não há referências às demais instituições financeiras regionais, apesar da semelhança de objetivos e da experiência acumulada.
\end{abstract}

Palavras-chave: Banco do Sul, Integração Financeira, Integração da América do Sul, Instituições Financeiras Regionais, Bancos de Desenvolvimento.

Abstract: The article analyzes the process of creation of Banco do Sul (South Bank), since the initial proposal, launched by Venezuela and Argentina in 2007, up to the definition of its capital and statutes, in mid 2009, with five more countries - Bolivia, Brazil, Ecuador, Paraguay and Uruguay. The project raises many questions. The diversity of goals submitted by the presidents was overcome when the Bank was defined as a development bank, advocated by Brazil, but broader objectives are still being mentioned. The institutional root of the proposal is reduced and the two principal members, Brazil and Venezuela, give conflicting signals about its commitment to the proposal. It is unclear how the Bank will gain strength with reduced capital and a difficult decision-making mechanism, given the political differences between governments. There are no references to other regional financial institutions, despite the similarity of objectives and accumulated experience.

Keywords: South Bank, Financial Integration, South America Integration, Regional Financial Institutions, Development Banks.

(*) Versão resumida do trabalho de mesmo título a ser publicado no livro Os novos rumos do regionalismo na América do Sul, Javier Vadell, Paris Yeros e Taiane Campos (orgs.), Belo Horizonte: Editora da PUC-MG.

${ }^{* *}$ ) Pontifícia Universidade Católica de São Paulo — PUC/SP. Carlos Eduardo Carvalho: professor do Departamento de Economia e do curso de Relações Internacionais. E-mail: cecarv@uol.com.br. Gabriel Kaneko: graduado em Relações Internacionais. E-mail: gabriel_cadu@yahoo.com.br. Carolina Pedroso: graduanda em Relações Internacionais. E-mail: c.silvapedroso@gmail.com. Allan Gabriel: graduandoem Relações Internacionais.E-mail: allan_bgabriel@yahoo.com.br. A pesquisa foi desenvolvida no âmbito do Grupo de Pesquisa em Moeda, Finanças e Desenvolvimento Econômico. Recebido em 24.8.09 e aceito em 16.10.09. 


\section{INTRODUÇÃO}

O processo de criação do Banco do Sul ganhou dinamismo surpreendente em 2007, culminando com a assinatura festiva da Ata de Fundação em Buenos Aires em 9 de dezembro, véspera da posse de Cristina Kirchner na Presidência da Argentina. Algumas questões sobre a natureza do Banco tinham sido encaminhadas ao longo do ano, com a definição do perfil de Banco de Desenvolvimento, defendida pelo Brasil.

A rapidez do avanço da proposta em 2007 pareceu desmentir o ceticismo inicial, mas o processo entrou em marcha bem mais lenta em 2008, diminuindo a presença do Banco do Sul nas declarações dos governos, à medida que as negociações enfrentaram temas complexos, ligados à estrutura de capital e aos mecanismos decisórios e de governança.

No primeiro semestre de 2009 veio afinal à luz a proposta de estatuto, ainda a ser aprovada pelos Presidentes e pelos Legislativos dos países envolvidos, mas persistem muitas dúvidas sobre o perfil e o alcance do Banco. Não se sabe, por exemplo, como a nova instituição poderá ganhar força com capital reduzido e mecanismo decisório difícil, diante das consideráveis diferenças entre os governos envolvidos, tanto em questões políticas como no tratamento de temas econômicos cruciais. Acrescente-se que, nas declarações e documentos sobre o novo Banco, não há referências às instituições financeiras regionais já existentes, apesar de estarem voltadas para papéis semelhantes aos atribuídos ao Banco e de reunirem considerável experiência na área.

Ainda assim, a aceitação da proposta e a tramitação rápida sugerem a presença de processos profundos e complexos a impulsionar a iniciativa. Uma indicação óbvia neste sentido é o quadro econômico peculiar configurado a partir de 2002-2003 na América Latina, com posição cambial superavitária e forte acumulação de reservas externas, ao lado do desgaste das políticas ditas neoliberais e da hostilidade da região ao FMI e às agências multilaterais. No plano político, a busca de unidade regional ganhou dinâmica própria e vem se sobrepondo às diferenças acentuadas entre os governos em temas cruciais, como as relações com o sistema financeiro internacional. Não se sabe como os desdobramentos da crise financeira mundial influenciarão este quadro e como os países envolvidos tratarão o Banco do Sul no contexto internacional delineado pela crise.

Este trabalho analisa a criação do Banco do Sul, partindo da singularidade do processo em curso, em que os elementos originais do quadro sul-americano atual recomendam cautela na avaliação de sua natureza e de suas perspectivas. O tema é discutido em três seções, além desta Introdução. A primeira apresenta um histórico da proposta e das negociações e expõe os entendimentos diferenciados a ela atribuídos pelos governos envolvidos, a partir da análise de declarações públicas e dos documentos oficiais disponíveis. A segunda traz um painel das instituições existentes na região, com a natureza de sua atividade e os montantes operados, de forma a situar o quadro financeiro e institucional que cercará o Banco na sua área de atuação. A terceira seção discute o contexto singular em que surgiu a proposta e destaca os desafios colocados pelo quadro político da América do Sul, em especial para a governança do novo Banco, com um painel de soluções adotadas em organizações semelhantes em outras regiões. Segue-se uma seção de comentários finais. 


\section{A PROPOSTA E SEUS SIGNIFICADOS}

\section{AS ORIGENS E O DESENVOLVIMENTO DA PROPOSTA}

A proposta de criação do Banco do Sul foi lançada por Hugo Chávez, que declarou ter se inspirado no relatório da Comissão Sul, ${ }^{(1)}$ criada em 1987 por dirigentes políticos e intelectuais para analisar e propor soluções para problemas dos países em desenvolvimento. A criação do Banco do Sul foi incluída na campanha eleitoral de 1999 (MCELHINNY, 2007), mas só foi encaminhada em 2004 (MARTÍNEZ VIAL, 2007), anunciada pelo discurso do Ministro das Relações Exteriores da Venezuela, Jesús Arnaldo Pérez, na UNCTAD XI:

Seguimos convencidos de la necesidad de crear un 'Banco del Sur' en donde pudiéramos centralizar nuestras reservas, permitiendo un acceso menos costoso para aquellos países hermanos que las necesitan. Y, sobre todo, para aliviarles del peso de las estrictas políticas de ajuste que nos imponen el Banco Mundial o el Fondo Monetario Internacional a través de sus cláusulas de condicionalidad. De esa forma, podríamos frenar la terrible sangría de nuestros recursos financieros hacia el Norte cuando son tan necesarios aquí, en el Sur (UNCTAD, 2004).

As negociações foram conduzidas em dois âmbitos. As reuniões técnicas multilaterais debateram aspectos técnico-operacionais (governabilidade, estrutura de capital), sem divulgação das atas. As reuniões ministeriais produziram Declarações, a serem assinadas pelos presidentes.

Em 21.2.07, Hugo Chávez e Néstor Kirchner assinaram o primeiro memorando de entendimento, fixando o prazo de 120 dias para a constituição do Banco. Bolívia e Equador tornaram-se membros e outros países permaneceram reticentes.

O Brasil aderiu ao projeto em maio e, em negociações bilaterais, convenceu os demais países a retomarem as negociações a partir do estágio inicial. ${ }^{(2)}$ Para o Presidente Lula:

É preciso definir, antes de qualquer coisa, o que é esse Banco do Sul: se tem finalidade semelhante à do FMI, do Banco Mundial, do BNDES. Primeiro é preciso definir para quê nós queremos um banco, qual a sua finalidade, para depois saber se compensa participar ou não. ${ }^{(3)}$

A Declaração de Quito, em 3.5.07, convidou todos os países da UNASUL e a Declaração de Assunção (22.5.07) aprovou a participação igualitária dos países. Também em Assunção, reunião paralela dos ministros do Mercosul incorporou o Banco à agenda do bloco e o Uruguai ratificou em junho.

(1) Proposta inicialmente feita pelo Primeiro-Ministro da Malásia, Mahatir Mohamad, e liderada pelo então presidente da Tanzânia, Julius K. Nyerere.

(2) Para o jornal argentino Página 12, 9.5.09: "Al comienzo Brasil llegó a decir que la iniciativa carecía de consistencia técnica y sugirió crear un fondo de estabilización regional que actuara como prestamista de última instancia frente a una eventual crisis de pagos. El temor era que Chávez utilizara el banco para disputarle el liderazgo en la región, pero finalmente bajó la guardia y se integró".

(3) Agência Brasil: <http://www.agenciabrasil.gov.br/noticias/2007/05/11/materia.2007-05-11.4742554330/view>. Acesso em: 18 fev. 2008. 
O passo definitivo veio em 8.10.07, quando sete países assinaram a Ata Fundacional, a Declaração do Rio de Janeiro. A Ata marcou a assinatura dos presidentes para 3.11.07, adiada posteriormente para 9.12.07, véspera da posse de Cristina Kirchner. Reunidos em Buenos Aires, em clima de empolgação, os presidentes assinaram o nascimento do Banco do Sul. No dia seguinte, o presidente do Uruguai assinou a Ata e a Colômbia confirmou sua participação. Decidiu-se que o Banco teria sede em Caracas, com duas subsedes, em Buenos Aires e La Paz.

Na sequência, a Cúpula de Montevidéu (15.4.08) estipulou em US\$20 bilhões o capital autorizado e em US\$ 7 bilhões o capital subscrito. A Cúpula Ministerial de Buenos Aires, em junho, fixou o capital inicial em US\$ 10 bilhões: Argentina, Brasil e Venezuela, US\$ 2 bilhões cada; Uruguai e Equador, US\$ 400 milhões cada; Paraguai e Bolívia, US\$ 100 milhões cada. Os restantes US\$ 3 bilhões ficaram para os demais membros da Unasul: Peru, Colômbia, Chile, Suriname e Guiana, sem data para adesão.

A Cúpula de junho desenhou a estrutura (Conselho de Ministros, Conselho de Administração, Diretório e seu Comitê Executivo, Conselho de Auditoria) e ratificou o princípio de um país, um voto, decisão apoiada pela Venezuela, com resistências da Argentina e do Brasil. Nos Estatutos, aprovados em maio de 2009, a serem ainda submetidos aos governos e Parlamentos, manteve-se o princípio de um voto por país, mas exigido o apoio de $70 \%$ do capital subscrito para projetos acima de US\$ 70 milhões.

Questões relevantes seguem indefinidas, como as prioridades de atuação: para alguns, o setor de infraestrutura já conta com muitos investimentos multilaterais e o Banco deveria concentrar esforços em segurança alimentar, redução da pobreza, meio ambiente e redução das assimetrias entre os países, ao contrário das instituições financeiras internacionais (ORTIZ E UGARTECHE, 2008). Além disso, a Venezuela seria contrária ao financiamento de projetos de grandes companhias privadas.

Entre os temas sem acordo estariam as isenções fiscais para todas as operações do Banco e questões referentes à participação da sociedade civil em suas atividades.

\section{OS DIFERENTES SIGNIFICADOS E CONTEÚDOS ATRIBUÍDOS À PROPOSTA}

$\mathrm{O}$ andamento das negociações evidenciou importantes diferenças no entendimento dos governos sobre o Banco do Sul, envolvendo a natureza e as atribuições do Banco, suas relações com instituições financeiras multilaterais e mercados financeiros e aspectos importantes de sua atuação.

Uma instituição desse tipo pode ter basicamente os seguintes papéis:

a) banco de desenvolvimento: financiamento de projetos que requerem recursos em volume superior ao disponível para os sócios; requer aporte capital dos sócios mais ricos e captação de recursos nos mercados financeiros internacionais e junto a governos e outras instituições multilaterais; realiza empréstimos de maturação longa e necessita de capital elevado e captar recursos de longo prazo; 
b) banco de desenvolvimento social: financiamento de políticas públicas e projetos para cidadãos e empreendimentos de micro e pequeno porte; não requer capital elevado; necessita de grande número de funcionários, com operações pulverizadas e elevado custo de análise e acompanhamento;

c) banco de reservas ou emprestador de emergência: garantir liquidez aos bancos centrais dos países-membros em situações de crise cambial ou financeira; requer elevado montante de recursos com alta liquidez, para viabilizar ação rápida e impactante em momentos de crise;

d) banco de compensação de pagamentos regionais: oferecer liquidez para negócios e transações financeiras entre os países sócios; reduzir a dependência de moeda estrangeira ou de moeda dos sócios mais fortes; requer reservas confiáveis em moedas fortes e liquidez elevada para garantir a confiança em suas operações de apoio às transações cambiais dos países-membros.

Pelo desenvolvimento das negociações, o Banco do Sul será tipo "a", banco de desenvolvimento, com algumas atribuições sociais do tipo " $b$ ". Contudo, discursos dos presidentes e documentos das negociações reiteram expectativas de que o Banco atue como banco de reservas ou como banco de compensação regional.

Quanto às relações com mercados financeiros e as agências financeiras multilaterais, a divergência está ligada ao repúdio às políticas neoliberais e à atuação do FMI na região, com posições fortemente hostis de Venezuela, Bolívia, Equador e Paraguai.

As posições da Argentina foram mais moderadas. Na reunião de fevereiro de 2007, Néstor Kirchner defendeu a possibilidade de cooperação com empresas internacionais interessadas em investimento produtivo.

O Brasil adotou desde o início uma linha de menor enfrentamento e de moderação. Apesar de insistir no papel do Banco para reduzir a dependência em relação a recursos externos e às instituições financeiras internacionais, em nenhum momento Lula levantou o tom do discurso contra as instituições e os mercados.

Sobre a estrutura decisória e os critérios para concessão de créditos, Chávez destacou a vontade política: "los técnicos hacen falta, pero los técnicos no son los que deben tomar las decisiones". O tom de Kirchner foi outro: "la región necesita una construcción colectiva independientemente del pensamiento político de cada Gobierno".

Em declarações da Venezuela e da Bolívia apareceram sinalizações de que o Banco não deveria impor condicionalidades e de que poderia haver operações a fundo perdido. O Brasil, ao contrário, se opôs a que países tomem empréstimos que excedam sua capacidade de pagamento.

A proposta inicial de Caracas era que o Banco apoiaria países em crise cambial, com base nas reservas dos países da região, e substituiria progressivamente o FMI. Para o ministro Mantega, o Banco será "um banco de desenvolvimento que financiará projetos de infraestrutura" e que, "para o caso de uma crise, permanece o FMI". O Equador defendeu que o Banco do Sul deveria ser também o embrião de uma moeda única regional, 
proposta ligada às dificuldades para sair da dolarização oficial adotada no país desde 2000. A Bolívia também defendeu a moeda única, mas defendeu também um Banco financiador de projetos sociais para redução da pobreza.

\section{A CONSOlidaÇão do PERFIL de BANCO DE DESENVOLVIMENTO}

As definições sobre o perfil de atuação do Banco foram se tornando mais precisas e mais curtas ao longo das negociações, com predomínio da posição brasileira. A Declaração de Quito definiu o perfil de banco de desenvolvimento e as prioridades para investimentos em infraestrutura, integração regional, redução de assimetrias entre os países e dentro deles e do hiato de desenvolvimento entre a região e os países centrais.

A Declaração de Assunção, em 22.5.07, reforçou a definição de banco de desenvolvimento, mas anunciou este perfil no primeiro de quatro objetivos, sem deixar claro se os objetivos 2 e 3 têm alguma relação com o Banco do Sul ou são objetivos a serem desenvolvidos por outras instituições ou outros acordos:

1. Dar prioridad a la definición de los estatutos para la constitución del Banco del Sur como Banca de Desarrollo.

2. Avanzar en el concepto de Fondo de Estabilización y Garantías con la integración de nuevos socios a fondos existentes y o creación de nuevos instrumentos.

3. Avanzar en el desarrollo de un sistema monetario regional que podría iniciarse con el comercio bilateral en monedas domésticas, tal como lo están implantando Argentina y Brasil.

4. Invitar a todas las naciones que conforman la UNASUR a integrar el Banco del Sur, proveyéndoles toda la información al respecto.

O fundo de estabilização (item 2) poderia ser o FLAR (ver seção 2) e o sistema monetário regional poderia ser pensado a partir dos pagamentos em moedas nacionais; o sistema foi criado por Brasil e Argentina, mas a Declaração não separa esses objetivos do que é proposto para o Banco do Sul.

O caráter de banco de desenvolvimento foi reiterado na Declaração do Rio de Janeiro, em 8.10.07, mas lhe atribui papel central em uma "nova arquitetura financeira regional", sem defini-la, e também o papel de provedor de liquidez, o que, em geral, não cabe a bancos de desenvolvimento, e sim a bancos centrais:

Los Ministros coincidieron en que la nueva institución será un banco de desarrollo con carácter suramericano con un rol central en el marco de una nueva arquitectura financiera regional. Reiteraron la expectativa de que el Banco contribuya a la elevación de la disponibilidad de liquidez, a la revitalización de la inversión, la corrección de las asimetrías, al desarrollo de la infraestructura integradora, a la promoción del empleo y a la activación de un círculo virtuoso de crecimiento económico en la región. 
Na cerimônia festiva de assinatura da Ata de Fundação do Banco do Sul, em Buenos Aires, em 9.12.07, as diferenças de entendimento ficaram nítidas em alguns discursos.

O presidente da Bolívia reiterou as posições do seu país:

...siento que este banco nos va a permitir resolver nuestros problemas económicos. Un Banco del Sur que no solamente (...) créditos a Estados, sino a empresas públicas y empresas sociales (...). Es el primer paso (...) para que Suramérica tenga su propia moneda, una moneda única (...).

O presidente do Equador apresentou com clareza a proposta de atribuir ao Banco do Sul objetivos mais amplos:

Desde la declaración de Quito (...) hemos iniciado esta nueva fase de integración latinoamericana, orientada hacia la construcción de una nueva arquitectura financiera regional, consistente en el Banco del Sur como corazón de una red de bancos de desarrollo, reorientados hacia un esquema alternativo, la articulación de los bancos centrales latinoamericanos en torno al Fondo del Sur como eje central; y la convergencia hacia un esquema monetario común, a partir del desarrollo de un sistema de pagos sustentado en una moneda de cuenta regional. (...)

O Banco do Sul teria então o duplo caráter de holding de banco de desenvolvimento e de banco central regional, depositário das reservas externas dos países e eixo para a construção do sistema monetário comum que conduz à formação da moeda regional.

Não houve referências ao Banco do Sul nas falas de Hugo Chávez e de Néstor Kirchner, enquanto Cristina Kirchner e Nestor Duarte fizeram declarações genéricas.

O Presidente do Brasil explicitou claramente a visão oposta à de Morales e de Correa, mas também mencionou objetivos mais amplos:

...um banco de fomento genuinamente sul-americano, (...) que pudesse financiar projetos em setores-chave de nossas economias, como infraestrutura, ciência e tecnologia, além de promover o desenvolvimento social com projetos voltados à redução da pobreza e das assimetrias da região. Com ele, vamos superar limitações de acesso a financiamentos junto a bancos multilaterais de fomento e bancos privados. (...) passo importante para fortalecer a autonomia financeira da América do Sul. (...) A solidez, a viabilidade e, principalmente, a eficácia do Banco do Sul dependerão de práticas e critérios firmes e críveis de governança e administração que combinem, de forma justa e equilibrada, os princípios da representação paritária e da proporcionalidade. Iniciativas como a criação de um fundo de estabilização para países com desequilíbrio na balança de pagamentos, de um sistema de pagamentos em moeda local e de um fundo sul-americano de garantias são projetos que poderão diminuir a dependência de nossa região, frente ao sistema financeiro internacional, e consolidar as relações econômico-financeiras entre nossos países. 


\section{O QUE JÁ EXISTE NA REGIÃO: BANCOS DE DESENVOLVIMENTO E INSTITUIÇÕES FINANCEIRAS MULTILATERAIS}

INSTITUIÇÕES DE DESENVOLVIMENTO NACIONAIS NA AMÉRICA LATINA

\begin{tabular}{|c|c|c|c|c|c|c|c|}
\hline \multicolumn{8}{|c|}{$\begin{array}{c}\text { Esquema } 1 \text { - Trajetória simplificada dos } \\
\text { bancos de desenvolvimento na América Latina (séc. xx) }\end{array}$} \\
\hline \multicolumn{8}{|l|}{ Contexto } \\
\hline CRISE de 29 & $\begin{array}{l}2^{\text {a }} \text { GUERRA } \\
\text { MUNDIAL }\end{array}$ & \multicolumn{4}{|c|}{ Guerra Fria } & \multicolumn{2}{|c|}{$\begin{array}{c}\text { Onda Neoliberal } \\
\text { na Am. Lat. }\end{array}$} \\
\hline $\begin{array}{l}\text { Recessão } \\
\text { mundial }\end{array}$ & $\begin{array}{l}\text { Fluxo de bens } \\
\text { manufaturados } \\
\text { interrompido }\end{array}$ & \multicolumn{2}{|c|}{$\begin{array}{l}\text { Organismos } \\
\text { multilaterais começam } \\
\text { a exercer influência na } \\
\text { Am. Lat. }\end{array}$} & \multicolumn{2}{|c|}{$\begin{array}{l}\text { Crises do } \\
\text { Petróleo geram } \\
\text { o endividamento } \\
\text { externo }\end{array}$} & $\begin{array}{l}\text { Refo } \\
\text { Libe }\end{array}$ & $\begin{array}{l}\text { formas } \\
\text { eralizantes }\end{array}$ \\
\hline \multicolumn{8}{|l|}{ Anos } \\
\hline & & & & & & & $\rightarrow$ \\
\hline 30 & 40 & 60 & 70 & & 80 & & 90 \\
\hline $\begin{array}{l}\text { Criação } \\
\text { sistemática } \\
\text { de bancos } \\
\text { de } \\
\text { fomento }\end{array}$ & $\begin{array}{l}\text { Nova etapa } \\
\text { na criação } \\
\text { destes } \\
\text { bancos, } \\
\text { com maior } \\
\text { flexibilidade }\end{array}$ & $\begin{array}{l}\text { Novas } \\
\text { estratégias de } \\
\text { desenvolvimento } \\
\text { endógeno, como } \\
\text { a substituição de } \\
\text { importações }\end{array}$ & $\begin{array}{l}\text { Acesso } \\
\text { crédito } \\
\text { comerc } \\
\text { predon }\end{array}$ & $\begin{array}{l}\text { ao } \\
\text { cial } \\
\text { nina }\end{array}$ & $\begin{array}{l}\text { Carência } \\
\text { de recursos } \\
\text { oficiais e } \\
\text { privados } \\
\text { leva ao } \\
\text { endividament } \\
\text { e até a fusão } \\
\text { com outras } \\
\text { instituições }\end{array}$ & & $\begin{array}{l}\text { Nova } \\
\text { concepção } \\
\text { de bancos } \\
\text { de fomento, } \\
\text { com atitudes } \\
\text { mais } \\
\text { reflexivas } \\
\text { e menos } \\
\text { dogmáticas }\end{array}$ \\
\hline
\end{tabular}

A trajetória dos bancos de desenvolvimento no continente pode ser resumida pelo Esquema 1. Depois da quebra da bolsa de Nova Iorque em 1929, os governos da América Latina sentiram-se pressionados a investir nas instituições financeiras de desenvolvimento. Desta forma, as primeiras instituições de fomento surgiram com o objetivo de superarem a debilidade do mercado de capitais latino-americano, que era pouco desenvolvido e não satisfazia as demandas de investimento, isto é, não oferecia créditos de médio e longo prazos.

O papel dos bancos de fomento começou a ser questionado a partir dos anos 1970, com o predomínio progressivo de teses contrárias ao desenvolvimentismo e à intervenção estatal. Passou-se a atribuir o baixo desenvolvimento dos mercados financeiros à existência de instituições públicas (CALDERÓN ALCAS, 2005), também abaladas pela instabilidade econômica do período. Os bancos de desenvolvimento foram orientados para um novo modelo, baseado em maior rentabilidade, custos menores e maior seletividade. Em vários países os bancos estatais foram privatizados ou extintos, mas alguns voltaram a criá-los recentemente, como a Bolívia e a Venezuela.

O Brasil foi uma exceção e o BNDES é o mais citado como exemplo para o Banco do Sul, pela atuação e pelo tamanho, já que desembolsa por ano o dobro do Banco Mundial e quatro vezes mais do que o Banco Interamericano de Desenvolvimento (Quadro 1). 


\section{Quadro 1 - Indicadores do BNDES, KDB, KfW, BID E Banco Mundial (2005)}

\begin{tabular}{|l|c|c|c|c|c|}
\hline \multicolumn{1}{|c|}{ ITENS } & BNDES & BID & BANCO MUNDIAL & KDB & KFW \\
\hline Ativos Totais & 74,7 & 65,3 & 222,0 & 109,6 & 258,4 \\
\hline Patrimônio Líquido & 6,7 & 18,7 & 38,5 & 16,3 & 10,3 \\
\hline Lucro & 1,4 & 0,7 & 3,8 & 2,4 & 0,5 \\
\hline Desembolsos & 20,0 & 4,9 & 9,7 & n.a. & n.a. \\
\hline Número de Empregados & 1.932 & 1.852 & $>10.000$ & 2.036 & 3.740 \\
\hline
\end{tabular}

FONTE: BNDES, Banco Interamericano de Desenvolvimento (BID), Banco Mundial, Korean Development Bank (KDB) e Kreidntaltanlt fur Weidawfban (KfW). In: TORRES FILHO (2007)(4).

Luciano Coutinho, presidente do BNDES, revelou recentemente que buscaria fazer acordos com o BID (Banco Interamericano de Desenvolvimento) e com o BIRD (Banco Mundial), a fim de obter recursos tanto para projetos nacionais como para os de integração sul-americana. Neste ponto é perceptível um distanciamento do BNDES com o que se está querendo definir para o Banco do Sul, uma vez que Chávez e Kirchner deixaram claro que não desejam se aproximar destes organismos para conseguir recursos.

\section{AS INSTITUIÇÕES FINANCEIRAS MULTILATERAIS LATINO-AMERICANAS}

"A América Latina e o Caribe contam talvez com a rede regional mais completa de banco multilaterais do mundo em desenvolvimento" (CEPAL, 2002, p. 172), composta por diversos bancos e fundos: Banco Interamericano de Desenvolvimento (BID), enquanto no sub-regional destacam-se o Banco Centro-Americano de Integração Econômica (BCIE), o Banco de Desenvolvimento do Caribe (BDC), a Corporação Andina de Fomento (CAF), o Fundo Financeiro para o Desenvolvimento da Bacia do Prata (FONPLATA), e o Banco Latino-Americano de Exportações (BLADEX), o Fundo Latino-Americano de Reservas (FLAR) e o Fundo de Convergência Estrutural do Mercosul (FOCEM).

Estes bancos multilaterais têm a capacidade de captar recursos nos mercados financeiros internacionais e oferecê-los aos países-membros com prazos maiores e juros menores que os praticados nos mercados privados. Para tanto, contam com boa avaliação de risco nos mercados e asseguram garantias parciais de risco e de crédito para cobrir riscos políticos e de câmbio, por exemplo.

Credibilidade é uma questão-chave para a criação, atuação e manutenção das instituições financeiras multilaterais. As garantias do compromisso dos países em honrar seus compromissos e a gestão cautelosa do capital da instituição são fatores importantes para uma boa avaliação. Além disso, a participação dos Estados Unidos, Japão e 16 países

(4) O KDB e o KfW são os bancos de desenvolvimento da Coreia e da Alemanha, respectivamente. 
europeus como membros efetivos do BID ampliam a credibilidade da organização para os mercados. Contudo, trata-se também de uma questão de custos e benefícios, mas à custa de terem o poder de interferir substancialmente na sua administração. No BID, o poder de voto dos países-membros é diretamente proporcional à parcela do capital da instituição subscrito pelo país ${ }^{(5)}$.

Já com relação ao perfil do empréstimo, este é muito diversificado. De modo geral, as instituições regionais dão prioridade aos projetos de desenvolvimento social. Ultimamente, os projetos ligados ao desenvolvimento e integração da rede de infraestrutura regional, conforme estabelecido pela iniciativa Integração da Infraestrutura Regional Sul-Americana $\left(\right.$ IIRSA) ${ }^{(6)}$, tem ganho muito relevância.

Essa tendência reflete a necessidade de recuperação do setor de infraestrutura depois de décadas de investimentos insuficientes. Segundo o presidente do BID, Luis Alberto Moreno, para a América Latina e o Caribe atingirem o nível das economias mais dinâmicas da Ásia, como a China e a Coreia do Sul, os países da região precisam investir no setor o dobro dos atuais $2 \%$ do PIB por ano durante um período de $20 \operatorname{anos}^{(7)}$.

Os objetivos do FONPLATA, por exemplo, estão intrinsecamente associados às metas estabelecidas pela IIRSA. O Convênio Constitutivo da instituição estabelece o objetivo de "apoiar técnica e financeiramente a realização de estudos, projetos, programas, obras e iniciativas que tendem a promover o desenvolvimento harmônico e a integração física dos países-membros" ${ }^{\prime(8)}$. Do início de suas atividades até o fim de 2006, fez empréstimos, para o setor público e privado, de US\$ 714 milhões.

De fato, os investimentos do FONPLATA parecem ser modestos frente aos desafios da região, bem como os efetuados por outras organizações. Para se ter uma dimensão, o BID no ano de 2007 aprovou investimentos de cerca de US\$ 9,6 bilhões para a região, confirmando, assim, o seu posto de maior fonte de financiamento multilateral para a América Latina e Caribe. Por outro lado, algumas instituições sub-regionais, apesar de suas limitações, exercem influência maior que as regionais e mesmo as internacionais (Banco Mundial). A CAF, entre o período de 1995-2000, transformou-se na maior fonte de recursos dos países da região andina (TITELMAN, 2005). Essa posição manteve-se entre 2002 e 2006, quando a CAF gerou US\$ 11.737 milhões do total de US\$24.453 milhões aprovados por todas as entidades multilaterais, o que corresponde a $48 \%$.

Como aponta a CEPAL, o caso da CAF é particularmente importante, pois seus acionistas são na maioria países e bancos da região. "Este fato, junto à boa qualidade das carteiras que em geral exibem os bancos multilaterais, indica que os agentes privados

(5) O Brasil e a Argentina possuem 900.154 ações cada, o que lhes conferem 900.289 votos (10\% do total de votos). Nos dois extremos do sistema de votação do BID, o país com maior poder de voto são os Estados Unidos (30,7\%) e o menor é Belize (0,111\%).

(6) Surgida em 2000, a IIRSA pretende ser um fórum de diálogo entre órgãos responsáveis por infraestrutura (transporte, energia, comunicações) nos países da América do Sul.

(7) Dados retirados do portal de notícias da própria Instituição. Disponível em: <http://www.iadb.org/NEWS/articledetail. $\mathrm{cfm}$ ? artid=4289\&language $=$ Po $>$. Acesso em: 10 jan. 2008.

(8) Ver o "Tratado da Bacia do Prata". Disponível em: <http://www.fonplata.org/www/pdf/tratadocp.pdf>. Acesso em: 20 jan. 2008. 
tendem a superestimar o risco principal, embora não unicamente durante os períodos de crise. Esta superestimação do risco constitui, por si só, uma falha de mercado que justifica a ação dos bancos multilaterais de desenvolvimento" (CEPAL, 2002, p. 171).

\section{Instituições de apoio aos Bancos Centrais, ao COMÉrCio e À integraÇão FINANCEIRA}

A América Latina conta também com algumas instituições voltadas para a área financeira e monetária. Os Convênios de Crédito Recíproco - CCR, criados nos anos 1960 no âmbito da ALADI, são instrumentos que permitem a realização de pagamentos de operações comerciais sem o dispêndio de moedas fortes, por meio da contabilização entre os bancos centrais para liquidação posterior (RÜTTIMANN et al., 2008; RODRIGUES, s/d). O modelo básico dos CCR contém os elementos centrais do mecanismo de pagamentos em moedas nacionais firmado entre o Brasil e a Argentina no final de 2008. Trata-se de mecanismos que permitem a contabilização dos pagamentos entre os países associados, sem dispêndio imediato de dólares, mas a compensação posterior é feita em dólares, entre os bancos centrais. A utilização dos CCR oscilou bastante ao longo dos anos, com maior interesse em momentos de dificuldades cambiais para a região.

Muitos autores têm destacado a importância de instituições regionais capazes de prover financiamento do balanço de pagamentos em detrimento de uma arquitetura internacional estruturada em um único fundo global. Nesse sentido, além de mecanismos localizados, a região conta com o Fundo Latino-Americano de Reservas, o FLAR, citado por vezes ao lado da Iniciativa Chiang Mai (CUNHA, BICHARA, 2005; UGARTECHE, 2008).

A principal vantagem das instituições regionais é que estas poderiam evitar o chamado "efeito contágio", como ocorreu nas crises de 1997 e 1998, ao alterar as expectativas e o comportamento dos agentes financeiros com relação aos países da região. Urrutia Montoya (2007) destaca o trâmite rápido dos empréstimos do FLAR, uma grande vantagem nos casos de riscos de crise cambial. Além disso, o FLAR coloca exigências muito menores na concessão de créditos, ao contrário das famosas condicionalidades do FMI.

$\mathrm{O}$ apoio do FLAR e de outras instituições dessa natureza tem sido um complemento e não um substituto do FMI (CEPAL, 2002). Não obstante, para economias de menor porte, como a Bolívia e o Equador, o auxílio do FLAR é tão importante quanto ao do FMI. Uma tarefa muito importante para a manutenção da estabilidade macroeconômica dos países-membros do FLAR, que não é desempenhada pelo FMI, é a contribuição que a entidade faz para amortizar as políticas monetárias/financeiras facilitando o cumprimento dos compromissos adquiridos (URRUTIA MONTOYA, 2007).

\section{CONTEXTO POlítico E ECONÔMICO, RECURSOS, GOVERNANÇA}

A proposta do Banco do Sul surgiu em um contexto econômico internacional muito favorável, acompanhado pelo desgaste do FMI e das políticas econômicas ditas "neoliberais" (CARVALHO, 2008) e pela aproximação entre os países da região. No plano econô- 
mico, contudo, a crise financeira internacional afetou a "bonança cambial" que permitiu a acumulação de reservas externas e ampliou os graus de liberdade nas políticas econômicas. Da mesma forma que na "bonança", a crise não trouxe mudanças significativas nas políticas econômicas dos países (CARVALHO et al., 2009). No plano político, a ênfase na unidade e o avanço da cooperação convivem com conflitos e disputas importantes.

\section{O CONTEXTO ECONÔMICO INTERNACIONAL E AS INDAGAÇÕES COLOCADAS PELA CRISE}

Nos anos da bonança econômica internacional, de 2002 a 2007, a liquidez abundante estimulou a disposição ao risco nos mercados financeiros (CINTRA, CAGNIN, 2007), o que ampliou muito a oferta de recursos e de investimento direto. Os países da região ganharam com preços de commodities, comércio intrarregional e demanda por seus produtos industrializados e semimanufaturados (BLÁZQUEZ-LIDOY, RODRÍGUEZ, SANTISO, 2006; JIMÉNEZ, TROMBEN, 2006; MARCHINI, 2006).

O duplo movimento favorável levou à geração de superávits externos sucessivos até em países com forte tendência a desequilíbrios cambiais, como Argentina e Brasil. A percepção da restrição externa como principal ponto de estrangulamento, como era tradicional na América Latina, foi substituída pela percepção de "un nuevo limitante para el crecimiento: la insuficiencia de infraestructura y la necesidad de una canalización y asignación de los recursos en forma consistente con un proceso de desarrollo sostenible" (MIERES, TRUCCO, 2008. p.1). As elevadas reservas em dólares apareceram como riqueza disponível, à espera de utilização por governos premidos por grandes demandas de crescimento econômico e de bem-estar social, e sob risco de serem afetadas pela desvalorização e pelos questionamentos do papel do dólar como moeda mundial.

O quadro externo favorável coincidiu com o desgaste das políticas "neoliberais" dos anos anteriores, criticadas por gerar poucos benefícios econômicos para a maioria da população, além de crescimento instável e baixo e graves crises cambiais e financeiras. Este contexto de frustrações estava na origem da eleição de Hugo Chávez na Venezuela, em 1998, e estimulou a vitória eleitoral de candidatos de esquerda em diversos países nos anos seguintes. Os novos governos, contudo, tinham poucos planos específicos e concretos para a política econômica de seus países, mesmo aqueles que nasceram com o propósito de "refundar o Estado" ou de implodir o sistema de partidos existente. Houve poucas mudanças na política econômica praticada, além de algumas medidas de distribuição de renda e de reforço das políticas sociais. A Argentina foi uma exceção, já que a crise catastrófica de 2001-2002 impôs a improvisação de uma política econômica nova (CARVALHO, 2008). A conduta mais comum foi manter a política econômica anterior, em alguns casos com grande cautela, de modo a conquistar a confiança dos mercados financeiros e do grande capital, como no Brasil.

A crise internacional provocou recessão generalizada, retração do comércio mundial e declínio acentuado dos preços das commodities. Até meados de 2009, as economias da região foram afetadas de forma menos grave do que se temia e não houve mudanças significativas de política econômica nos diversos países, mas seguem em aberto os questionamentos sobre a natureza e a intensidade dos impactos no curto e no médio prazo. 
O quadro mais negativo seria a volta da restrição cambial como problema relevante para a política econômica, no caso de queda da receita de exportações e retração da liquidez mundial e do financiamento externo. No cenário mais benigno, a crise nos países centrais estimularia as regiões periféricas a buscarem políticas defensivas, como na Ásia depois de 1997 (CUNHA, BICHARA, 2005), com ênfase na demanda doméstica e na cooperação regional.

\section{DESAFIOS DO QUADRO POLÍTICO: A ÊNFASE NA INTEGRAÇão E OS CONFLITOS PERSISTENTES}

O quadro de aproximação e integração na América do Sul foi decisivo para que a proposta do Banco do Sul ecoasse entre os governos, mas o discurso pela unidade, muito forte entre os presidentes originados na esquerda, não eliminou os conflitos na região.

Não foram poucas as disputas entre países latino-americanos nos anos recentes: a questão das papeleiras, entre Argentina e Uruguai; a nacionalização das reservas naturais da Bolívia, com apoio do presidente da Venezuela, contra a Petrobrás; os desentendimentos entre os países do Mercosul em diversas questões comerciais; o contencioso envolvendo Equador, Venezuela e Colômbia no caso das FARC; a violação da soberania equatoriana por parte da Colômbia; os problemas envolvendo a empresa brasileira Odebrecht no Equador. Episódio pouco lembrado foi a atitude de indiferença mantida pelo governo brasileiro, em 2003 e 2004, no conflito da Argentina com credores externos e instituições financeiras internacionais em torno da dívida externa em moratória.

Além de conflitos localizados, há uma disputa permanente entre Brasil e Venezuela em torno da liderança regional. O Brasil tem reivindicado o papel de representante dos países em desenvolvimento nas negociações internacionais, como na OMC. O país luta para ganhar projeção externa como produtor da "energia limpa" dos biocombustíveis, tema em que se opõe a Venezuela, muito dependente das exportações de petróleo.

Desde sua posse, em 1999, o presidente Chávez investiu na América Latina, com um discurso "anti-imperialista" apoiado na alta do petróleo. A Argentina recebeu ajuda da Venezuela na crise financeira, da mesma forma que Bolívia e Cuba nos anos seguintes. O presidente do Equador se apoia na Venezuela para criar um arranjo monetário que permita ao Equador sair da dolarização oficial, apesar das reticências com algumas iniciativas chavistas.

Para muitos observadores, a criação do Banco do Sul foi uma vitória de Chávez sobre o Brasil, ${ }^{(9)}$ inclusive pela indicação de Caracas como sede do Banco, já que o Brasil preferia Montevidéu. No sistema de votação, a Venezuela defendia o princípio de "um país, um voto", aceito no Estatuto aprovado em maio de 2009, mas com a ressalva de voto qualificado em operações acima de determinado valor.

O Brasil conseguiu vitórias importantes na definição do Banco como instituição de desenvolvimento, contra a proposta venezuelana de emprestador de última instância

(9) BBC Brasil. Banco do Sul é vitória de Chávez frente ao Brasil, diz El País. Disponível em: <http://www.bbc.co.uk/portuguese/reporterbbc/story/2007/10/071010_pressreview.shtml>. Acesso em: 20 dez. 2007. 
regional, e na delimitação das atividades do Banco à América do Sul. Para o El País, "a diplomacia brasileira queria evitar (...) a ideia de Chávez de que o Banco servisse também para ajudar a outros aliados de fora da região, como Cuba e Nicarágua, em programas assistencialistas de fundo ideológico e político"(10).

Outra questão de grande relevância é como o Banco do Sul atravessaria uma mudança no quadro político da América do Sul. Por ora não existem garantias de que o banco seja autossustentável e independente dos arranjos das forças políticas nos sete países que o compõem.

\section{RELAÇÕES COM SOCIEDADE CIVIL, MERCADOS E TOMADORES DE CRÉDITO}

O sucesso do Banco do Sul dependerá, em grande medida, da capacidade de alavancar recursos para assumir papel financeiro relevante na região. Além do capital aportado pelos países-membros, o Banco deveria ser capaz de mobilizar recursos de outras fontes, o que vai depender de suas relações com os mercados financeiros, com os organismos internacionais e com os capitais privados da própria região. O acesso a estas fontes será condicionado pelas atitudes dos governos e pela condução dos negócios do Banco, em termos de destinação, controle dos resultados e transparência.

Como fontes de recursos, o Banco pode contar com: (i) aporte de capital pelos membros, com recursos das reservas externas ou de fontes fiscais; (ii) empréstimos dos países ao Banco; (iii) captação nos mercados internacionais; (iv) captação nos mercados domésticos.

O Banco nascerá com capital inicial de US\$ 7 bilhões, sendo US\$ 6 bilhões divididos igualmente entre Argentina, Brasil e Venezuela. Vincular a contribuição ao peso econômico do país é coerente com o propósito de reduzir as assimetrias na região, mas cria o problema do peso nas decisões. A proposta inicial de "um país, um voto" foi mantida, mas a versão preliminar do Estatuto, de maio de 2009, introduziu a necessidade de votos correspondentes a pelo menos $2 / 3$ do capital subscrito para projetos acima de US\$ 70 milhões. É uma inovação diante do modelo das instituições financeiras internacionais, onde o voto é proporcional à contribuição do país. Por esse sistema, os sete países-membros do Banco do Sul detêm, em conjunto, 3,99\% dos votos no FMI e 5,1\% no Banco Mundial, enquanto os EUA detêm 17\% e 16,4\% dos votos, respectivamente (Quadro 2), o que lhes dá poder de veto nos temas relevantes em que são requeridos $85 \%$ dos votos para aprovação.

A participação equitativa dos países no Banco tem a preocupação de se distanciar do modelo proporcional das instituições financeiras internacionais. Porém, existe a preocupação de que as assimetrias relacionadas ao capital aportado criem relações de dependência com os países menores. Durante as negociações, o Brasil manifestou certa relutância à ideia de direitos iguais com contribuições desiguais e propôs que os países fizessem contribuições iguais, em torno de US\$ 200 milhões a US\$ 500 milhões (MARTÍNEZ VIAL, 2007), o que deixaria o Banco com dimensões muito reduzidas. Ao

(10) Ver nota 1. 
mesmo tempo que o Brasil critica a gestão das instituições financeiras internacionais por serem demasiadamente elitizadas e luta para aumentar sua participação acionária nelas, assumiu com reservas a definição de voto igualitário no Banco do Sul.

\section{Quadro 2 - Contribuição e proporção de votos de países no FMI, BM e BID}

\begin{tabular}{|c|c|c|c|c|c|c|c|c|c|}
\hline & 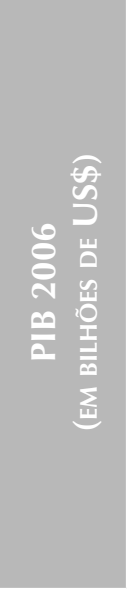 & 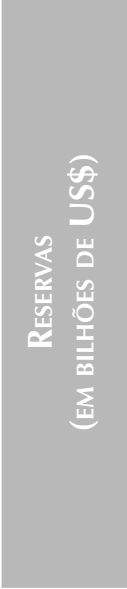 & 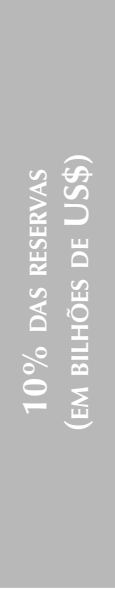 & 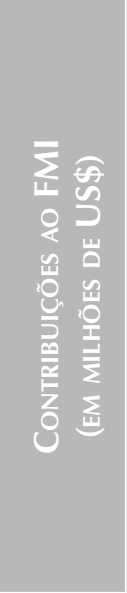 & 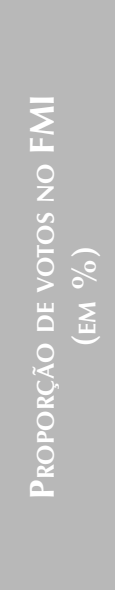 & 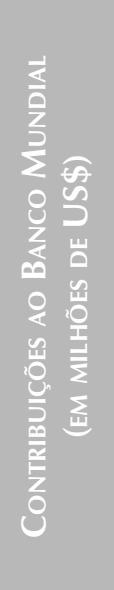 & 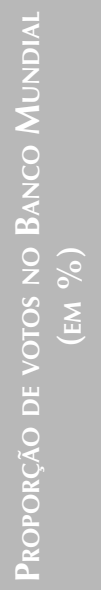 & 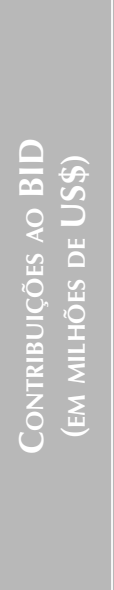 & 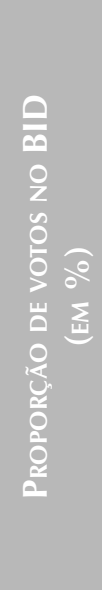 \\
\hline Brasil & 1.100 & 163 & 16.3 & 536.6 & 1.40 & 245.5 & 2.1 & 465.1 & 10.75 \\
\hline Argentina & 214 & 43.2 & 4.32 & 502.4 & 0.97 & 132.2 & 1.1 & 465.1 & 10.75 \\
\hline Venezuela & 182 & 35 & 3.5 & 497.7 & 1.20 & 150.8 & 1.3 & 249.3 & 5.76 \\
\hline Equador & 41 & 3.5 & 0.35 & 51.8 & 0.14 & 18.2 & 0.2 & 24.9 & 0.60 \\
\hline Uruguai & 19 & 3.5 & 0.35 & 78.5 & 0.15 & 18.6 & 0.2 & 49.9 & 1.15 \\
\hline Paraguai & 9 & 1.5 & 0.15 & 22 & 0.05 & 6.6 & 0.1 & 18.7 & 0.43 \\
\hline Bolívia & 11 & 4.4 & 0.44 & 42.4 & 0.08 & 10.8 & 0.1 & 37.3 & 0.87 \\
\hline Total: 7 países & 1.576 & 254.1 & 25.41 & 1.731 .4 & 3.99 & 582.7 & 5.1 & 1.310 & 30.31 \\
\hline Estados Unidos & 13.200 & 69.181 & 6.918 & 7.691 & 17.10 & 1.998 & 16.4 & 1.303 & 30 \\
\hline
\end{tabular}

Os negociadores equatorianos defenderam que as cotas de cada membro não deveriam ser menores que as contribuições destinadas ao FMI, ao Banco Mundial e ao BID. Porém, como apontou McElhinny (2007), não ficou definido se essas contribuições se referiam a uma única instituição em particular, ou se às três combinadas.

Para Marcos Cintra $^{(11)}$, a proposta de comprometer parcelas das reservas internacionais para capitalizar a instituição é muito difícil de ser refutada, diante do elevado volume acumulado nos últimos anos. Contudo, existem alguns problemas domésticos para a utilização dessa fonte de recursos, a começar pela ausência de leis que regulamentem a utilização das reservas para financiar um banco regional (MCELHINNY, 2007). 
Essa dificuldade pode ser imputada à menor relevância atribuída à legitimação institucional de decisões dessa natureza, mas reflete também o desafio de legitimar o uso no exterior de recursos tidos como muito necessários internamente. Um exemplo são as críticas internas enfrentadas por Chávez por financiar muitos projetos na América Latina.

A possibilidade de financiamento do Banco pela captação de recursos nos mercados ou junto a governos e instituições dos países centrais enfrenta restrições consideráveis, em decorrência dos significados atribuídos por vários governos à proposta de Banco do Sul. Alguns dos países que lideram a formação do Banco têm como bandeira a contestação dos mercados financeiros, tratados com pouca consideração ou hostilidade.

Há ainda a questão das regras de administração do ativo, em especial na recuperação dos créditos. Com regras de cobrança "frouxas" e juros subsidiados, o Banco correria riscos de se enfraquecer financeiramente. O Brasil tem insistido para o Banco não proteger tomadores de empréstimos que não honrem seus compromissos (MCELHINNY, 2007, p. 7) e que a gestão e a saúde financeira do Banco são determinantes em suas ambições.

\section{REFERÊNCIAS EXTERNAS}

Bancos regionais de desenvolvimento existem há décadas na África, na Ásia e nos países islâmicos, e o Banco Europeu data de 1958. Esta subseção analisa experiências de organização e gestão de quatro bancos de desenvolvimento: Banco Europeu de Desenvolvimento (BEI), Banco Asiático de Desenvolvimento (ADB), Banco Africano de Desenvolvimento (AfDB) e o Banco Islâmico de Desenvolvimento (IsDB) ${ }^{(12)}$.

Do ponto de vista da governança, os quatro apresentam estrutura semelhante: um Conselho de Governadores, um Conselho de Administradores e um Presidente, com exceção do BEI, que possui também um Comitê Executivo.

Em linhas gerais, todos os poderes do Banco são dados ao Conselho de Governadores, que formula as diretrizes de políticas de crédito, além de eleger ou nomear o Conselho de Administradores. Os Conselhos de Governadores se diferenciam pelo número de membros e pelo poder de voto de cada um. Os Bancos incluem participação proporcional ao capital aportado, mas há fórmulas que reduzem o peso dos países com maiores contribuições, com o poder de voto composto com uma porcentagem distribuída de forma igualitária e a outra parte proporcional ao capital aportado. O Banco Africano é o que mais concede poder aos membros com menos capital, seguido pelo Banco Islâmico e pelo Banco Asiático. No Banco Europeu, os membros possuem voto igualitário, mas as decisões são tomadas quando a maioria votante soma pelo menos $50 \%$ do capital subscrito.

O Conselho de Administração, formado por profissionais de alta competência em finanças, é responsável pela direção das operações gerais do Banco e pela concessão de créditos, pelas taxas de juros e pelas garantias requeridas.

(12) As siglas utilizadas estão em inglês, com exceção do BEI, que está em francês. 
O que diferencia este Conselho de um Banco para outro é o número de membros e as cadeiras do Conselho são distribuídas entre os países por votação. No ADB, AfDB(13) e no IDB, os administradores possuem poder de voto diferenciado, correspondente à quantidade de votos que contribuíram para sua eleição. No Banco Islâmico, a Câmara dos Administradores é composta por 14 membros, dos quais sete são escolhidos pelos países com maior quantidade de capital e os outros sete são eleitos pelo restante. O caso europeu é particular, pois o Conselho de Administradores é formado por um representante de cada membro (os 27 países da União Europeia) mais um administrador eleito pela Comissão Europeia.

Nos quatro casos, o Presidente é o representante legal do Banco e o chefe do Conselho dos Administradores, mas com poder de voto limitado a casos específicos. O Presidente tem como competência assegurar a gestão dos assuntos correntes do Banco, como organização e demissão de pessoal. O Presidente não pode ser governador nem administrador durante seu mandato e é eleito pelo Conselho dos Governadores por maioria do número de votos, mas desde que represente a maioria do poder de voto. O Banco Europeu possui um conselho a mais, o Comitê Executivo, composto por um presidente e oito vice-presidentes, nomeados pelo Conselho dos Governadores sob proposta do Conselho dos Administradores.

Os Bancos captam recursos nos mercados financeiros internacionais, com exceção do Banco Islâmico, que tem os países-membros como a principal fonte de recursos.

É importante destacar algumas experiências vividas por esses Bancos, para ampliar a reflexão sobre o Banco do Sul.

No seu nascimento, o Banco Africano teve também o otimismo e a predisposição dos líderes políticos para criar uma instituição regional, com a proposta de um Banco africano para os africanos, típica do "pan-africanismo" da época. O Banco, em 1964, em menos de dez anos teve sua primeira crise entre o Presidente e o Conselho de Administração. Até 1972, além de sofrer com a insuficiência de recursos financeiros (GHARBI, 2008), após este período, chamado de "fase exclusivamente africana", veio a fase chamada de pragmática.

Entre 1972 e 1982, o Banco procurou saídas para contornar a crise financeira sem abrir o capital a países que não fossem da região. Contudo, a solução não veio de dentro da região, e sim da criação de um fundo onde países não regionais pudessem colocar recursos, o Fundo Africano de Desenvolvimento (FAD). Nesta nova instituição as decisões eram tomadas à 50/50 (50\% BAD, 50\% PNR). Assim, o grupo recém-nascido (BAD + FAD) conseguiu triplicar suas operações.

Mesmo assim, em 1982 o Banco admite não poder perder mais tempo para abrir o capital aos parceiros não regionais. Assim, os países do FAD entram na administração do Banco e o capital saltou para US\$ 6,2 bilhões. Apesar da bonança financeira, o Banco não consegue evitar uma nova crise de liderança, entre o Presidente e o Conselho de Administração. O Banco só se recuperou anos depois, na chamada terceira fase, marcada pelo

(13) Sigla utilizada desse modo para diferenciá-la do Banco Asiático de Desenvolvimento. 
saneamento financeiro e a erradicação dos problemas de liderança. Um desafio do Banco hoje é fazer acreditar que, com $40 \%^{(14)}$ do poder de decisão com países não regionais, o Banco ainda continua africano e responde exclusivamente às necessidades regionais.

A experiência africana chama a atenção, entre outras coisas, para a necessidade de aumento de capital. Nesse sentido, ao pensar na atuação do Banco do Sul diante dessa demanda, o desafio cresce ainda mais com o sistema de governança: participação e contribuição financeira igualitária.

Isto porque, dentro da lógica governamental desenhada, é de esperar-se que o Banco, ao aumentar seu capital, cada membro o fez de maneira igual. Efetivamente, o aumento do aporte seria nivelado pelo país com "menor capacidade". Assim, ao considerar as assimetrias econômicas de cada país, tal sistema pode dificultar a capacidade de adaptar-se rapidamente às necessidades conjunturais.

Em 1999, por exemplo o BEI, por decisão do Comitê Executivo, recusou submeter-se às pesquisas do Escritório Europeu de Luta Antifraude (OLAF). Ele alegou que todo o controle externo seria contrário ao princípio de autonomia financeira do Banco (MARCHEGIANI, 2000). Este mesmo princípio justifica a não submissão das operações efetuadas sobre os próprios recursos do BEI à Corte de Contas Europeia.

Assim, o debate do BEI sobre o princípio de autonomia financeira convida a uma reflexão sobre: "Para quem o BEI é responsável?". A resposta a esta pergunta é que o Banco é um organismo público de direito comunitário cuja organização e o funcionamento são regrados pelos tratados europeus e o protocolo sobre o estatuto do Banco ${ }^{(15)}$.

\section{NOTAS FINAIS}

A criação do Banco do Sul continua envolta em muitas dúvidas sobre os objetivos da nova instituição, sobre seus mecanismos decisórios e sobre as orientações operacionais que serão adotadas.

O projeto nasceu marcado pelo voluntarismo político de importantes lideranças da região, uma proposta ambiciosa sem o detalhamento das condições de implantação e de operação, no que não destoa do estilo que prevaleceu na rápida e intensa aproximação dos países do Continente nos últimos anos. Nesse processo de integração regional singular, se a vagueza deu lugar a expectativas de que o movimento seria mais retórico que efetivo, os fatos até aqui colocam desmentidos importantes a essa avaliação pouco otimista. Embora os rompantes retóricos continuem marcando as falas de muitos governos, a integração tem avançado. A sustentação dos processos democráticos é um

(14) De acordo com o "pouvoir de vote en 31 décembre de 2005". Disponível em: <http://www.afdb.org/pls/portal/docs/ PAGE/ADB_ADMIN_PG/DOCUMENTS/FINANCIALINFORMATION/BAD\%20-\%20POUVOIRS\%20DE\%20VOTE\%20 31-12-05.PDF>. Acesso em: 2 mar. 2008.

(15) Question écrite n. 489/74, du 12 novembre 1974, de lord O’Hagan à la Commission des Communautés européennes, dans Journal officiel des Communautés européennes (JOCE). 7.3.75, n. C 55, p. 4. Disponível em: <www.ena.lu>. Acesso em: 3 mar. 2008. 
ganho de excepcional relevância e tem se ampliado. Pode-se argumentar que os avanços na integração se deveram ao contexto externo muito favorável, ameaçado desde 2008 pela crise internacional, mas a aproximação econômica tem avançado, apesar de alguns retrocessos e de muitas dificuldades, e apesar também de não haver convergências na política econômica.

É possível que o Banco do Sul surpreenda e ganhe consistência por corresponder a motivações para a integração regional mais profundas do que se pode perceber a esta altura e que só a paixão seria capaz de colocar em movimento, como afirmou o ex-presidente do Paraguai, Nicanor Duarte:

"de esto que estamos firmando del Banco del Sur, aquí se ha integrado de manera serena la pasión con la racionalidad, porque si sólo la pasión fuese el factor de referencia, podíamos cometer errores, así como si sólo la racionalidad priorizáramos podíamos terminar en el ámbito de la retórica simplemente, pero aquí hubo la capacidad de los líderes de integrar la pasión con la racionalidad".

Ainda assim, a racionalidade exige que sejam destacadas e analisadas as debilidades e indefinições que continuam sem respostas e sem discussão sistemática, nem mesmo nos foros adequados, pelo menos ao que se sabe.

Um aspecto muito relevante é a natureza do mandato que o Banco do Sul receberá de seus sócios e, por decorrência, o grau de autonomia que terá em relação às opções de política econômica que venha a adotar. Há muitas indagações sobre o enraizamento institucional que o Banco terá nos diferentes países. Nos sócios de maior relevância Argentina, Brasil e Venezuela —, a institucionalidade vigente apresenta diferenças substantivas e em nenhum deles a participação no Banco foi objeto de tramitação e aprovação em instâncias que garantam apoio consistente no caso de conflitos ou de necessidades novas para suas atividades. Seria o caso, por exemplo, de uma proposta de aumento de capital diante de um quadro de dificuldades ou, ao contrário, de um momento muito favorável para a expansão dos negócios. Esta fragilidade pode se tornar bem mais séria no caso de que possíveis sucessores dos atuais governos tenham entendimentos diferentes sobre a integração continental.

É difícil imaginar que uma instituição financeira multilateral possa crescer sem acordos básicos entre os parceiros em temas cruciais, como fontes de recursos, prioridades de destinação dos créditos, atitude frente à inadimplência. Os três temas dependem das regras de governança, ainda por definir, e também da legitimação do Banco diante da sociedade civil e das forças políticas representadas no Legislativo em cada país.

Neste terreno, dois dos principais governos envolvidos emitem sinais contraditórios sobre seu comprometimento com o Banco: o presidente da Venezuela anunciou a formação de outros dois bancos, um com países da América Central e outro com a Rússia, enquanto o Brasil anunciou em 2008 a criação do Fundo Soberano, ao qual seria destinada uma parte das reservas externas do país, sem qualquer referência a possíveis compromissos com o Banco do Sul. Além disso, em 2009 o Brasil decidiu emprestar US\$ 10 bilhões ao FMI, montante muito superior à sua contribuição para 
a formação do Banco. Essa atitude sugere que a estratégia de inserção externa do Brasil está mais voltada para ambições globais, em que se considera um líder "natural" da América do Sul. Nessa linha, seria mais promissor colocar dinheiro no FMI que no Banco do Sul, instituição em que o Brasil efetivamente apostou pouco desde seu início e em que se opôs sempre ao papel de emprestador de última instância, papel que o FMI teve e que agora procura restabelecer, com ajuda inclusive do aporte de reservas pelo Brasil.

Outros problemas decorrem das concepções e práticas divergentes e até contraditórias na política econômica, como se verifica entre Brasil e Venezuela. As diferenças envolvem as políticas domésticas, o relacionamento com os mercados financeiros internacionais e temas complexos e polêmicos, como o tratamento de divergências sobre direitos de propriedade e contratos, exigência de pagamentos de obrigações pelos devedores, entre outros.

A capacidade do Brasil de fazer valer seus pontos de vista pode ser uma demonstração de que os governos no Continente na prática aceitam as chamadas regras de mercado e se opõem a elas de forma apenas retórica, já que a hostilidade aos mercados internacionais não combina com a posição brasileira. Ainda assim, não se imagina como o Banco conseguiria financiamento externo com um discurso político tão conflituoso em sua base. Além disso, o Brasil é, ao mesmo tempo, um dos sócios que tem menos interesse na formação do Banco, por contar com financiamento externo e com uma instituição de fomento própria, capaz de atuar diretamente nos outros países da região em apoio a suas empresas e a seus interesses.

Um aspecto preocupante é o silêncio sobre as muitas instituições financeiras regionais já existentes, muitas delas com atividades semelhantes às que o Banco deverá desenvolver. As declarações dos proponentes do Banco do Sul e os documentos já divulgados não fazem referências a elas, nem objeções ou críticas, nem possibilidades de cooperação. Pode ser um reconhecimento implícito de que as bases de entendimento são estreitas e não suportariam a discussão aberta sobre os instrumentos regionais existentes, mas pode ser também a fantasia voluntarista de criar algo inteiramente novo, livre dos vícios do passado, ou o desejo de manejar livremente o elevado volume de reservas externas acumuladas na bonança cambial dos últimos anos.

Como será governado o Banco do Sul, como se dará a governança e o gerenciamento na base de um país, um voto, e com a exigência de maioria baseada no capital aportado para projetos acima de US\$ 70 milhões? Quais interesses serão atendidos, quando houver desacordo e as preferências divergirem? Uma resposta a esses dilemas é de que prevalece a vontade da maioria, a essência do modelo democrático. Porém, tratando-se de um Banco, deve prevalecer a maioria com peso econômico ou a maioria numérica? A proposta de votos igualitários dos diversos países indica que o Banco só poderá crescer se os três sócios com maior peso econômico estiverem de acordo com as decisões adotadas, o que requer a disposição dos três de aceitar compromissos e restrições para preservar a unidade do empreendimento. Volta-se à questão do enraizamento do Banco no quadro institucional e no grau de comprometimento das forças políticas nacionais com o projeto. 
Diante destas dúvidas, surgem propostas de que as dúvidas e divergências só poderão ser equacionadas quando se colocar o Banco em funcionamento e que o mais importante agora é avançar nas definições básicas e começar a operar. Para Ortiz e Ugarteche (2008), por exemplo, o Banco deveria iniciar logo suas operações, o que requer que os países-membros solucionem suas disputas internas e ponham em marcha a proposta, pois "es mejor un Banco imperfecto, que ningún banco".

O ritmo das reuniões de 2008 e 2009 sugere um caminho distinto, com discussões progressivas sobre os pontos mais difíceis. É possível que a montagem de uma equipe técnica permanente pudesse agilizar o processo, com delegação de poderes pelos países envolvidos.

De imediato, seria muito útil aumentar a divulgação dos trabalhos realizados, de modo a permitir maior envolvimento das forças políticas e das organizações da sociedade nos vários países. Um resumo das discussões realizadas ajudaria a compreender as diferenças de entendimento e poderia facilitar a apresentação de propostas e a explicitação de críticas que, cedo ou tarde, colocarão a proposta à prova dos embates políticos da região.

\section{REFERÊNCIAS BibLIOGRÁFICAS}

AGOSIN, Manuel R. Fortalecimiento da la cooperación financiera regional. Revista de la Cepal, Santiago de Chile, n. 73, p. 33-53, abr. 2001.

BLÁZQUEZ-LIDOY, Jorge; RODRÍGUEZ, Javier; SANTISO, Javier. Ángel o demónio? Los efectos del comércio chino en los países de América Latina. Revista de la Cepal, Santiago de Chile, n. 90, p. 17-43, dic. 2006.

CALDERÓN ALCAS, Romy. La banca de desarrollo en América Latina y el Caribe. Serie Financiamiento des Desarrollo, Santiago, Cepal, n. 157, p. 38, 2005.

CARVALHO, Carlos Eduardo. Esquerda conflitiva e política econômica: notas sobre Argentina, Bolívia e Venezuela. In: AYERBE, Luis F. (Org.). Novas lideranças políticas e alternativas de governo na América do Sul. São Paulo: UNESP e Programa San Tiago Dantas de Pós-Graduação em Relações Internacionais da Unesp, Unicamp, PUC/SP, 2008. p. 183-198.

; ALMEIDA, Mariana; WOCHLER, Regiane; BRAGA, Camila; PEDROSO, Carolina. A América Latina e a crise: impactos iniciais e primeiras reações. Política Externa, São Paulo, Paz e Terra, Gacint-USP, IEEI, v. 17, n. 4, p. 47-62, mar./maio 2009.

CEPAL. Globalização e desenvolvimento. LC/G.2157(SES.29/3)/P, 2002.

CINTRA, Marcos Antonio M.; CAGNIN, Rafael F. Evolução da estrutura e da dinâmica das finanças norte-americanas. Econômica, Niterói, v. 9, n. 1, p. 89-131, jun. 2007.

CUNHA, André M.; BICHARA, Julimar S. Integração monetária e financeira em regiões emergentes: a experiência recente do Pacífico Asiático pode servir de inspiração para o Mercosul? Economia e Sociedade, Campinas, v. 14, 2 (25), p. 235-262, 2005.

GHARBI, Samir. Les raisons d'internationaliser la Banque africaine de développement. Jeune Afrique, 3 février. 2008.

JIMENEZ, Juan P.; TROMBEN, Varínia. Política fiscal y bonanza: impacto del aumento de los precios de los productos no renovables en América Latina y el Caribe. Revista de la Cepal, Santiago de Chile, n. 90, p. 61-86, dic. 2006. 
MARCHEGIANI, Giannangelo. La BEI et l'OLAF, un conflit de nature constitutionnelle. Revue du Marché commun et de l'Union européenne, p. 690-695, n. 443, déc., 2000. Disponível em: <http:// www.ena.lu>. Acesso em: 3 mar. 2008.

MARCHINI, Jorge. ¿Quien financia a quien hoy en America Latina? Primer Simposio Internacional sobre Deuda Pública, Auditoria Popular y Alternativas de Ahorro e Inversión para los pueblos de América Latina, 2006.

MARTÍNEZ VIAL, María José. ¿Lógica o desafio? Política Exterior, Madrid, n. 119, p. 29-33, sept./ oct., 2007.

MCELHINNY, Vince. El Banco del Sur. Bank Information Center, nov. 2007. Disponível em: <http:// www.bicusa.org/en/Article.3587.aspx>. Acesso em: 10 fev. 2007.

MIERES, Fabíolo; TRUCCO, Pablo. El financiamiento para el desarrollo y la reforma del sistema financiero internacional. Una mirada desde América Latina. Buenos Aires: Fundación Friedrich Ebert - FES, p. 37, 2008.

ORTIZ, Isabel; UGARTECHE, Oscar. El Banco del Sur: avances y desafios. 2008. Disponível em: $<$ http://www.obela.org/system/files/El+Banco+del+Sur+Ortiz+Ugarteche+Octobre+08.pdf $>$. Acesso em: 12 nov. 2008.

RODRIGUES, Maria G. O convênio de créditos reciprocos da ALADI e a integração regional. mimeo. (s/d).

RÜTTIMANN, André; SENRA, Andressa; KOBLITZ, Arthur; FERREIRA, Leonardo; ZERAIK, Marcio; CAMINHA, Rafael; MENESES NETO, Themistocles. CCR: seu papel no financiamento à infraestrutura. Revista do BNDES, Rio de Janeiro, BNDES, v. 14, n. 29, p. 81-114, 2008.

TITELMAN, Daniel. La banca de desarrollo y el financiamiento productivo. Serie Financiamiento del Desarrollo, Santiago, Cepal, v. 137, p. 30, 2005.

TORRES FILHO, Ernani. Os bancos de desenvolvimento e a experiência recente do BNDES. Visão do Desenvolvimento, Rio de Janeiro, BNDES, v. 28, p. 8, 2007.

UGARTECHE, Oscar. Entre la realidad y el sueño. La construcción de una arquitectura financiera sudamericana. Nueva Sociedad, Buenos Aires, FES, n. 217, p. 4-23, 2008.

URRUTIA, Montoya. Perspectivas del fondo latinoamericano de reservas. Serie Financiamiento del Desarrollo, Santiago, Cepal, n. 191, p. 21, 2007.

\section{Documentos}

Declaração de Assunção. 2007. <http://mef.gov.ec/pls/portal/docs/PAGE/MINISTERIO_ECONOMIA_FINANZAS_ECUADOR/INTEGRACION\%20_SUDAMERICANA/ARCHIVOS2007/DECLARACIONDEASUNCION.PDF>. Acesso em: 30 jan. 2007.

Declaração de Quito. 2007. <http://www.cadtm.org/spip.php?article2630>. Acesso em: 29 jan. 2007. Declaração do Rio de Janeiro. 2007. <http://mef.gov.ec/pls/portal/docs/PAGE/MINISTERIO_ECONOMIA_FINANZAS_ECUADOR/INTEGRACION\%20_SUDAMERICANA/ARCHIVOS2007/ DECRIODEJANEIRO.PDF>. Acesso em: 18 jan. 2008.

\section{Sites}

Banco Centro-Americano de Integração Econômica: <http://www.bcie.org/spanish/index.php>.

Banco de Desenvolvimento do Caribe: <http://www.caribank.org/>.

Banco Interamericano de Desenvolvimento: $<$ http://www.iadb.org/?lang=pt >.

Banco Latino-Americano de Exportações: <http://www.blx.com/>. 
Corporação Andina de Fomento: <http://www.caf.com/view/index.asp?ms=17>.

Fundo Financeiro para o Desenvolvimento da Bacia do Prata: <http://www.fonplata.org/www/ index2.html>.

Fundo Latino-Americano de Reservas: <https://www.flar.net/contenido/default.aspx>.

Venezuela/UNCTAD XI. 2004:<http://www.unctadxi.org/sections/u11/docs/GeneralDebate/15ven_ spa.pdf>. Acesso em: 29 jan. 2008. 